\title{
GMR
}

\section{MNS, Duffy, and Kell blood groups among the Uygur population of Xinjiang, China}

\author{
G.Y. Lin, X.L. Du, J.J. Shan, Y.N. Zhang Y.Q. Zhang and Q.H. Wang \\ Blood Transfusion Department, People's Liberation Army 474th Hospital, \\ Urumqi, Xinjiang Uyghur Autonomous Region, China \\ Corresponding author: G.Y. Lin / Q.H. Wang \\ E-mail: linguoyue_yy@163.com / 19691126wqh@163.com
}

Genet. Mol. Res. 16 (1): gmr16019176

Received September 6, 2016

Accepted February 14, 2017

Published March 15, 2017

DOI http://dx.doi.org/10.4238/gmr16019176

Copyright $(92017$ The Authors. This is an open-access article distributed under the terms of the Creative Commons Attribution ShareAlike (CC BY-SA) 4.0 License.

\begin{abstract}
Human blood groups are a significant resource for patients, leading to a fierce international competition in the screening of rare blood groups. Some rare blood group screening programs have been implemented in western countries and Japan, but not particularly in China. Recently, the genetic background of $\mathrm{ABO}$ and $\mathrm{Rh}$ blood groups for different ethnic groups or regions in China has been focused on increasingly. However, rare blood groups such as MN, Duffy, Kidd, MNS, and Diego are largely unexplored. No systematic reports exist concerning the polymorphisms and allele frequencies of rare blood groups in China's ethnic minorities such as Uygur and Kazak populations of Xinjiang, unlike those on the Han population. Therefore, this study aimed to investigate the allele frequencies of rare blood groups, namely, MNS, Duffy, Kell, Dombrock, Diego, Kidd, Scianna, Colton, and Lutheran in the Uygur population of Xinjiang Single specific primer-polymerase chain reaction was performed for genotyping and statistical analysis of 9 rare blood groups in 158 Uygur individuals. Allele frequencies were compared with distribution among other ethnic groups. Observed and expected values of genotype frequencies were compared using the chi-square test. Genotype frequencies obeyed the Hardy-Weinberg equilibrium $(\mathrm{P}>0.5)$ and
\end{abstract}

Genetics and Molecular Research 16 (1): gmr16019176 
allele frequencies were stable. Of all subjects detected, 4 cases carried the rare phenotype $\mathrm{S}^{-}$of MNS blood group (frequency of 0.0253), and 1 case carried the phenotype $\mathrm{JK}^{\mathrm{a}-\mathrm{b}-}$ (frequency of 0.0063 ). Frequencies of the four groups, MNS, Duffy, Dombrock, and Diego, in the Uygur population differed from those in other ethnic groups. Gene distribution of the Kell, Kidd, and Colton was similar to that in Tibetan and Han populations, though there were some discrepancies. Gene distribution of Scianna and Lutheran groups showed monomorphism similar to that in Tibetan and Han populations. These findings could contribute to the investigation of the origin, evolution, and hematology of Uygur population of Xinjiang and assist in screening of rare blood groups in ethnic minorities, meeting of clinical blood supply demands, and building of the national rare blood group library.

Key words: Uygur population; Rare blood group; Genotyping; Allele frequency; PCR-SSP; Xinjiang

\section{INTRODUCTION}

Human blood is as valuable as oils and rare earth elements and considered an integral part of national strategic resources (Yang et al., 2014). The International Society of Blood Transfusion has officially recognized 33 human erythrocyte blood group systems, which include over 300 inheritable blood group antigens (Ji et al., 2012). The international competition in the screening of rare blood groups is fierce (Chen et al., 2014). While the rare blood group screening programs have been implemented in western countries and Japan, much has yet to be done to accomplish this task in China.

Frequencies of rare blood group antigens are believed to vary significantly with race and ethnicity. For example, the frequency of RhD-negative blood types is $20 \%$ in individuals of European-descent, $10 \%$ in equatorial races, $0.4 \%$ in Mongolians, and only $0.3 \%$ in China's Han ethnic group. In the MN blood group system, blood type M is dominant in North China, while blood type N is dominant in South China (Shulman, 1990). This blood group is not only associated with hemolytic transfusion reactions and hemolytic disease of the newborn, but also with the occurrence of hypertension (Delanghe et al., 1995). The positive rate of $\mathrm{Mi}^{\mathrm{a}}$ antigen is as high as $24.7 \%$ among the Dai people in Xishuangbanna, Yunnan Province, while the positive rate of $\mathrm{Mi}^{\mathrm{a}}$ antigen is only $5.4 \%$ in the Han population of Shanghai. The overall positive rate of $\mathrm{Di}^{\mathrm{a}}$ antigen in the Chinese population is as high as $9 \%$. Association of the hemolytic transfusion reaction and hemolytic disease of the newborn with the anti-Dia antibody has been reported previously (Liu, 2011).

The $\mathrm{Jk}(\mathrm{a}-\mathrm{b}-)$ phenotype of the Kidd blood group has been reportedly found in the Macao Blood Center (Liu, 2011). The other four phenotypes are Jk (a+b-), Jk (a-b+), Jk $(\mathrm{a}+\mathrm{b}+)$, and $\mathrm{Jk}(\mathrm{a}-\mathrm{b}-)$. The $\mathrm{Jk}(\mathrm{a}-\mathrm{b}-)$ phenotype is very rare in any population. The frequency of the JK (a-b-) phenotype for the Chinese Han ethnic group is less than one in ten thousand (Ji et al., 2012; Chen et al., 2014), therefore, it is usually difficult to find matched blood for transfusions quickly.

Individuals with Fy(a-b-) phenotype of the Duffy blood group have been reported in blood centers in Qingdao and Inner Mongolia (Wang et al., 1993). In the Chinese Han

Genetics and Molecular Research 16 (1): gmr16019176 
ethnic group, the dominant phenotype is $\mathrm{Fy}(\mathrm{a}+\mathrm{b}-)$, accounting for $91 \%$, while the $\mathrm{Fy}(\mathrm{a}+\mathrm{b}+)$ phenotype accounts for only $9 \%$.

The Kell blood group antigen K1 is the most common alloantibody. Caucasian (British, American, etc.) Women, About $40 \%$ of women carrying the anti-Ki antibody will give birth to babies with severe hemolysis. In Europe and the United States blood transfusion treatment work, K original identification of blood transfusion routine items (Roychoudhury et al., 1988). Therefore, rare blood groups represent one of the major research topics.

China is a vast territory with many ethnic groups, and the distribution of blood groups vary significantly. For example, 13 ethnic groups have lived in Xinjiang for generations. The distribution of rare blood groups in Xinjiang displays unique features because of relative geographical isolation, interethnic marriages, and historical migration. Under ideal situations, the allele frequencies of a given population would remain stable across generations. However, in reality, allele frequencies of a population are constantly changing on account of gene mutation, gene recombination, natural selection, migration, and genetic drift, resulting in the continuous evolution within species. The evolution of a population can be characterized usually by allele frequency. This study focused on the allele frequencies of nine rare blood groups in the Uygur population of Xinjiang, including MNS, Duffy, Kidd, Diego, and Dombrock to understand the genetic make-up and blood relationship within the Uygur ethnic group. We hope the data obtained in the study can contribute to the analysis of the origin, fusion, and migration of the Uygur ethnic group, enriching the hematological and genetic studies of China's ethnic groups and the human race. The findings can be used to prepare for emergencies and build the rare blood group library.

\section{MATERIAL AND METHODS}

\section{Subjects}

A total of 158 inpatient and outpatient cases at the 474th Hospital of People's Liberation Army were considered for the study. The subjects were unrelated by blood for three generations. There were 92 males and 66 females, and their ages ranged from 1-84 years old (median 50.81). The experiment conformed to the PRC code of ethics for clinical trials. The experiment was approved by the hospital Ethics Committee (approval No.: SQS20140501). Blood samples were collected after obtaining informed consent from all study participants.

\section{Sample collection}

A total of 162 blood samples were collected between May 2014 to January 2015, seven monthly. A volume of $3.5 \mathrm{~mL}$ of blood was drawn from the median cubital vein from each subject and preserved with ethylenediaminetetraacetic acid (EDTA) anticoagulant. Four blood samples were excluded because of the presence of the anticoagulant heparin as this would affect DNA extraction. Thus, 158 samples were finally included. None of the subjects had hematological diseases, and most of them received blood type identification before blood withdrawal. The sample size, statistical design, and the types of kits used were determined by reference to similar studies of other ethnic minorities in China (Zhao and Li, 2009; Zhang et al., 2014). 


\section{Blood sample processing}

The whole blood samples containing the heparin were excluded. The concentration of the extracted DNA was 30-100 ng/ $\mu \mathrm{L}$. If the concentration was too high, the sample was diluted with Tris-EDTA buffer. DNA was diluted with Tris-EDTA buffer to a final concentration of 30$120 \mathrm{ng} / \mu \mathrm{L}$, with the optimal concentration of $30-50 \mathrm{ng} / \mu \mathrm{L}$. The $260 / 280$ purity ratio was $1.60-$ 1.80. The DNA samples must not be dissolved in EDTA with concentration above $0.5 \mathrm{mM}$. To ensure the integrity of the samples, they were transported below $4{ }^{\circ} \mathrm{C}$. The DNA samples were dissolved in 1X Tris-EDTA buffer (pH 8.0-9.0), and extracted genomic DNA samples were preserved at $-20^{\circ} \mathrm{C}$ for less than 1 year.

\section{Reagents and equipment}

\section{Reagents}

The polymerase chain reaction-sequence specific primer (PCR-SSP) blood typing kits for MNS, Duffy, Kell, Dombrock, Diego, Kidd, Scianna, Colton and Lutheran blood groups were manufactured by Tianjin Super Biotechnology Development Co., Ltd Tianjin city, in China. The whole blood genomic DNA extraction kit (PROTRANS, Hockenheim, Germany) and agarose (Biowest regular agarose G-10, Manufacturerd to specifications Distributed by GENE COMPANYLTD, ORIGIN:SPAIN) Taq polymerase $(5 \mathrm{U} / \mu \mathrm{L})$ was manufactured by Promega (Madison, WI, USA). Other reagents used were ethidium bromide $(10 \mathrm{mg} / \mathrm{mL}$, analytically pure), 1X TBE buffer (each component being analytically pure), and purified water (deionized water).

\section{Equipment}

Biosafety cabinet (Haier,Dalian city, in China); high-speed microcentrifuge TG16-W (Changsha Weierkang Xiangying Centrifuge, in China); HC-2515 high-speed centrifuge (USTC ZONKIA, Heifei city, in China); DYY-BC electrophoresis apparatus, electrophoresis tank, and WD-9413B gel imaging analysis system (Beijing Liuyi Instrument Factory, in China); BIO-RAD PCR instrument (model 580BR 6679, USA); continuous micro pipette (5$100 \mu \mathrm{L}$ ); vortex mixer; Midea microwave oven to heat the liquid to $100^{\circ} \mathrm{C}$.

\section{Methods}

\section{Genomic DNA extraction}

DNA extraction was performed in 17 steps according to the instruction of the PROTRANS DNA Extraction Kit. Genomic DNA concentration and purity were determined with an ultraviolet-visible (UV-Vis) spectrophotometer. The genomic DNA samples were preserved at $-20^{\circ} \mathrm{C}$ and detected in batches.

\section{PCR-SSP typing}

The specific primers were designed for the 9 rare blood groups via base substitution

Genetics and Molecular Research 16 (1): gmr16019176 
or deletion according to the sequences in the Genebank (The primer blood typing kits for MNS, Duffy, Kell, Dombrock, Diego, Kidd, Scianna, Colton and Lutheran blood groups were manufactured by Tianjin Super Biotechnology Development Co., Ltd Tianjin city, in China). Table 1. The 3,-terminal base of the sense primer was designed to allow amplification only if the base matches the template exactly. The conserved fragment of human growth hormone (HGH) gene was used to design the internal control primers. The internal control was added into each sample well and in each run.

First, the extracted genomic DNA was adjusted to the optimal concentration of 30-50 $\mathrm{ng} / \mu \mathrm{L}$. PCR procedures were as follows: $96^{\circ} \mathrm{C}$ for $2 \mathrm{~min}, 1 \mathrm{cycle} ; 96^{\circ} \mathrm{C}$ for $20 \mathrm{~s}, 68^{\circ} \mathrm{C}$ for $60 \mathrm{~s}$, 5 cycles; $96^{\circ} \mathrm{C}$ for $20 \mathrm{~s}, 65^{\circ} \mathrm{C}$ for $45 \mathrm{~s}, 72^{\circ} \mathrm{C}$ for $30 \mathrm{~s}, 10$ cycles; $96^{\circ} \mathrm{C}$ for $20 \mathrm{~s}, 62^{\circ} \mathrm{C}$ for $45 \mathrm{~s}$, $72^{\circ} \mathrm{C}$ for $30 \mathrm{~s}, 15$ cycles; $72^{\circ} \mathrm{C}$ for $3 \mathrm{~min}, 1$ cycle. The amplification products were preserved at $4{ }^{\circ} \mathrm{C}$. The reaction mix consisted of the followings: dNTP-Buffer $(440 \mu \mathrm{L}$ condensed dNTPBuffer $+560 \mu \mathrm{L}$ PCR-grade sterilized water $=1000 \mu \mathrm{L}$ ) with mixing and centrifugation. The mixture of buffer-enzyme-samples was prepared at a certain proportion. For each subject, the mixture was $220 \mu \mathrm{L}$ dNTP-buffer $+1.7 \mu \mathrm{L}$ Taq polymerase $(5 \mathrm{U} / \mu \mathrm{L})+25 \mu \mathrm{L}$ DNA sample $=246.7 \mu \mathrm{L}$, with mixing and centrifugation. Into each well (1-22 wells), $10 \mu \mathrm{L}$ of the above mixture was added. Paraffin oil $(15-20 \mu \mathrm{L})$ was also added into each well. The tube was properly capped and placed into the pre-configured PCR instrument. PCR programs were run according to the above steps. In the meantime, $2.5 \%$ agarose gel was prepared.

Table 1. Base pairs, sites of nucleotide mutation, and primers for the typing of the 9 rare blood groups.

\begin{tabular}{|c|c|c|c|c|c|}
\hline Rare blood group & Allele & Fragment length (bp) & Nucleotide mutation & Forward primer 5'-3' & Reverse primer 3'-5' \\
\hline \multirow[t]{4}{*}{ MNS } & $\mathrm{M}$ & 162 & $71 \mathrm{G} / \mathrm{A}$ & CAGCATCAAGTACCACTGGT & AGCTCGCATTTCTCAGTGTTTG \\
\hline & $\mathrm{N}$ & 300 & $72 \mathrm{~T} / \mathrm{G}$ & TCAGCATTAAGTACCACTGAG & AGCTCGCATTTCTCAGTGTTTG \\
\hline & $\mathrm{S}$ & 239 & $143 \mathrm{C} / \mathrm{T}$ & CGATGGACAAGTTGTCCCA & CATGTGGGTGGCACCCTGCC \\
\hline & $\mathrm{s}$ & 239 & $143 \mathrm{C} / \mathrm{T}$ & CGATGGACAAGTTGTCCCG & CATGTGGGTGGCACCCTGCC \\
\hline \multirow[t]{2}{*}{ Duffy } & Fy & 167 & $131 \mathrm{G} / \mathrm{A}$ & CAGCTGCTTCCAGGTTGGCAC & ATGTCCACAGTCACTCGCCA \\
\hline & $\mathrm{Fy}^{\mathrm{b}}$ & 167 & $131 \mathrm{G} / \mathrm{A}$ & CAGCTGCTTCCAGGTTGGCAT & ATGTCCACAGTCACTCGCCA \\
\hline \multirow[t]{2}{*}{ Kell } & K1 & 145 & $578 \mathrm{C} / \mathrm{T}$ & ACTCATCAGAAGTCTTTGCA & GCTCCCCCAGCCCCCGTCCG \\
\hline & K2 & 145 & $578 \mathrm{C} / \mathrm{T}$ & ACTCATCAGAAGTCTTTGCG & GCTCCCCCAGCCCCCGTCCG \\
\hline \multirow[t]{2}{*}{ Dombrock } & Do $^{a}$ & 182 & $793 \mathrm{G} / \mathrm{A}$ & ATTCGATTTGGCCAATTCCTT & GTTTACCCGTTCTGCTAA \\
\hline & Do $^{b}$ & 182 & $793 \mathrm{G} / \mathrm{A}$ & ATTCGATTTGGCCAATTCCTC & GTTTACCCGTTCTGCTAA \\
\hline \multirow[t]{2}{*}{ Diego } & $\mathrm{Di}^{\mathrm{a}}$ & 336 & $2561 \mathrm{C} / \mathrm{T}$ & GGGCCAGGGAGGCCA & CCTGCCAGCTCCATGTGAC \\
\hline & $\mathrm{Di}^{\mathrm{b}}$ & 336 & $2561 \mathrm{C} / \mathrm{T}$ & GGGCCAGGGAGGCCG & CCTGCCAGCTCCATGTGAC \\
\hline \multirow[t]{2}{*}{ Kidd } & $\mathrm{Jk}^{\mathrm{a}}$ & 244 & $838 \mathrm{G} / \mathrm{A}$ & CCCAGAGTCCAAAGTAGATGTC & CAGGACGGACAAAGGA \\
\hline & $\mathrm{JK}^{\mathrm{b}}$ & 244 & $838 \mathrm{G} / \mathrm{A}$ & CCCAGAGTCCAAAGTAGATGTCT & CAGGACGGACAAAGGA \\
\hline \multirow[t]{2}{*}{ Scianna } & Sc1 & 155 & $169 \mathrm{G} / \mathrm{A}$ & CCTCCTTGGGTACCGTTTCC & TCCTGTGGCAGCCTAAGAG \\
\hline & Sc2 & 155 & $169 \mathrm{G} / \mathrm{A}$ & CCTCCTTGGGTACCGTTTCT & TCCTGTGGCAGCCTAAGAG \\
\hline \multirow[t]{2}{*}{ Colton } & $\mathrm{Co}^{\mathrm{a}}$ & 191 & $134 \mathrm{C} / \mathrm{T}$ & GAACAACCAGACGGC & GTTTCTTGGAGCAGGTTAAACA \\
\hline & $\mathrm{Co}^{\mathrm{b}}$ & 191 & $134 \mathrm{C} / \mathrm{T}$ & GAACAACCAGACGGT & GTTTCTTGGAGCAGGTTAAACA \\
\hline \multirow[t]{4}{*}{ Lutheran } & $\mathrm{Lu}^{\mathrm{a}}$ & 173 & $230 \mathrm{G} / \mathrm{A}$ & CATCTCAGCCGAGGCTAAAAC & CTGCACTGTGAAGCTCTCAC \\
\hline & $\mathrm{Lu}^{\mathrm{b}}$ & 173 & $230 \mathrm{G} / \mathrm{A}$ & CATCTCAGCCGAGGCTAAAAT & CTGCACTGTGAAGCTCTCAC \\
\hline & $\mathrm{Au}^{\mathrm{a}}$ & 146 & $1615 \mathrm{~A} / \mathrm{G}$ & CACCTCAGTCACTCACGCGC & CTGCACTGTGAAGCTCTCCA \\
\hline & $\mathrm{Au}^{\mathrm{b}}$ & 146 & $1615 \mathrm{~A} / \mathrm{G}$ & CACCTCAGTCACTCACGCGT & CTGCACTGTGAAGCTCTCCA \\
\hline
\end{tabular}

\section{Electrophoresis}

Each amplified product $(5-10 \mu \mathrm{L})$ was loaded in a certain sequence onto a $2.5 \%$ agarose gel in about $100 \mathrm{~mL}$ of $0.5 \mathrm{X}$ TBE buffer. Electrophoresis was conducted under $150 \mathrm{~V}$ and $110 \mathrm{~mA}$ current for $12 \mathrm{~min}$. The electrophoresis stopped when the internal control bands and the positive bands were separated. The gel was stained with ethidium bromide, imaged, and analyzed.

\section{Quality control}

Each sample contained the internal control, which was a 429-bp conserved fragment 
of $H G H$. This internal control was run in each experiment and could be detected during electrophoresis. The amplified product of the internal control was also visible in the negative wells. The internal control bands in the positive wells were very weak or non-existent likely because the specific primers competed with internal control primers for substrates such as Taq polymerase during amplification.

PCR-SSP method is a qualitative assay and has extremely high detection sensitivity. Any improper operation will lead to false negative or false positive results. In addition to strict quality control measures (e.g., internal control), the experiment was repeated if the results were ambiguous for some alleles. All experimental results were reported and reviewed by two professionals experienced in matching in kidney transplantation using the PCR-SSP method.

\section{Result interpretation}

Intensity of the specific bands did not interfere with result interpretation since PCRSSP is a qualitative assay. The typing results were interpreted according to the standard typing result table (provided by Tianjin Super Biotechnology Development Co., Ltd. Tianjin city, in China.). Criteria for interpretation were as follows: 1) positive wells: simultaneous appearance of internal control bands and specific amplification bands was considered positive; 2) negative cells: appearance of only internal control bands, but no specific amplification bands, was considered negative; 3 ) appearance of neither internal control bands nor specific amplification bands was regarded as a failure, and a second detection was needed.

\section{Statistical analysis}

The SPSS 12.0 software (In the biological network to provide biological software, SPSS12.0 free version.) was used for statistical analysis. According to the Hardy-Weinberg principle, for a sufficiently large population of sexual reproduction, the allele frequencies will remain constant across generations if the individuals are allowed random breeding without gene mutation, introduction of new genes, or natural selection. Therefore, the sum of allele frequencies will be 1 , and the sum of all genotype frequencies will be 1 or $100 \%$. Now consider a diploid individual who has two alleles, $\mathrm{A}$ and $\mathrm{a}$, on one gene locus. The population has $\mathrm{N}$ such individuals. The number of individuals carrying AA, Aa, and aa genotypes is $\mathrm{n} 1, \mathrm{n} 2$, and $\mathrm{n} 3$, respectively. The following formulae were used for calculation: (1) frequency of A allele $=$ number of individuals carrying A allele/(number of individuals carrying A allele + number of individuals carrying a allele) $\mathrm{n} 1 / \mathrm{N}+\mathrm{n} 2 / 2 \mathrm{~N}$; (2) frequency of AA genotype $=$ number of individuals carrying AA genotype/total number of the diploid individuals in this population $=\mathrm{n} 1 / \mathrm{N} ;(3)$ and relationship between allele frequency and genotype frequency: frequency of allele $\mathrm{A}=$ frequency of AA genotype $+1 / 2$ frequency of Aa genotype.

In a natural population, the genotype frequencies are not calculated based on allele frequencies unless the relationship between the two obeys the Hardy-Weinberg equilibrium. The calculation formulae are as follows: 1) frequency of homozygous genotype is the square of the allele frequency, i.e., $\mathrm{AA}=\mathrm{A}^{2} ; 2$ ) frequency of heterozygous genotype is the product of frequencies of two alleles multiplied by 2 , i.e., $\mathrm{Aa}=\mathrm{Ax}$ a $\mathrm{x} 2 ; 3$ ) expected value of the frequency of homozygous genotype $=$ total number of individuals $x$ the square of the frequency of homozygous genotype; 4) expected value of the frequency of heterozygous genotype = the total number of individuals $\mathrm{x}$ the frequency of homozygous genotype $\mathrm{x}$ the frequency of

Genetics and Molecular Research 16 (1): gmr16019176 
heterozygous genotype $\mathrm{x} 2$; and 5) the expected and observed values of genotype frequencies were compared using the chi-square test to determine whether the Hardy-Weinberg equilibrium was reached. The calculation formula was chi-square $\left(\chi^{2}\right)=(\text { observed value - expected value })^{2} /$ expected value. $\mathrm{P}<0.05$ was considered to indicate a significant difference. The statistical processes were implemented by experienced researchers.

\section{RESULTS}

\section{Genotype frequencies of the 9 rare blood groups were in Hardy-Weinberg equilibrium in Uygur population}

The phenotype frequencies of the 9 rare blood groups obeyed the Hardy-Weinberg equilibrium in Uygur population, without significant difference in the expected and observed values of frequencies $(\mathrm{P}>0.05)$. The allele frequencies remained stable. Rare phenotypes were found in 2 rare blood groups, which were $\mathrm{S}^{-}$phenotype in 4 cases with a frequency of 0.0253 and $\mathrm{Jk}(\mathrm{a}-\mathrm{b}-)$ phenotype in 1 case with a frequency of 0.0063 . This has not been previously reported for the Uygur population. Monomorphism was found in the allele frequencies of Scianna, Colton, and Lutheran blood groups. A skewed distribution was apparent for the allele frequencies of Kell and Diego blood groups. Table 2 shows the phenotype frequencies of the other 4 rare blood groups.

\begin{tabular}{|c|c|c|c|c|c|c|}
\hline Rare blood group & Phenotype & Observed value (frequency) & Expected value (frequency) & Allele frequency & $\chi^{2}$ & $\mathrm{P}$ \\
\hline \multirow{7}{*}{ MNS } & $\mathrm{M}^{+} \mathrm{N}^{-}$ & $53(0.3354)$ & $52.99(0.3353)$ & 0.5791 & 0 & \multirow{6}{*}{$>0.05$} \\
\hline & $\mathrm{M}^{-} \mathrm{N}^{+}$ & $28(0.1772)$ & $27.99(0.1772)$ & 0.4209 & 0 & \\
\hline & $\mathrm{M}^{+} \mathrm{N}^{+}$ & $77(0.4873)$ & $77.02(0.4873)$ & 0.1743 & 0 & \\
\hline & $\mathrm{S}^{+} \mathrm{S}^{-}$ & $6(0.0380)$ & $4.80(0.0304)$ & 0.8009 & 0.300 & \\
\hline & $\mathrm{S}^{-\mathrm{s}^{+}}$ & $105(0.6646)$ & $101.35(0.6415)$ & & 0.131 & \\
\hline & $\mathrm{S}^{+} \mathrm{s}^{+}$ & $43(0.2725)$ & $44.11(0.2792)$ & & 0 & \\
\hline & $\mathrm{S}^{-} \mathrm{s}^{-}$ & $4(0.0253)$ & $7.74(0.0489)$ & & 1.807 & $>0.05$ \\
\hline \multirow[t]{3}{*}{ Duffy } & $\mathrm{Fy}^{\mathrm{a}+\mathrm{b}-}$ & $81(0.5127)$ & $77.29(0.4892)$ & 0.6994 & 0.178 & \multirow{3}{*}{$>0.05$} \\
\hline & $\mathrm{Fy}^{\mathrm{a}-\mathrm{b}+}$ & $18(0.1139)$ & $14.28(0.0904)$ & 0.3006 & 0.969 & \\
\hline & $\mathrm{Fy}^{\mathrm{a}+\mathrm{b}+}$ & $59(0.3734)$ & $66.44(0.4205)$ & 0.0158 & 0.833 & \\
\hline \multirow[t]{3}{*}{ Kell } & $\mathrm{K}^{1+2-}$ & $0(0)$ & $0.04(0.0002)$ & 0.9842 & & \multirow[t]{3}{*}{$>0.05$} \\
\hline & $\mathrm{K}^{1-2+}$ & $153(0.9684)$ & $153.00(0.9684)$ & 0.2342 & 0 & \\
\hline & $\mathrm{K}^{1+2+}$ & $5(0.03165)$ & $4.91(0.0311)$ & 0.7658 & 0 & \\
\hline \multirow[t]{3}{*}{ Dombrock } & $\mathrm{Do}^{\mathrm{a}+\mathrm{b}-}$ & $9(0.0570)$ & $8.67(0.0549)$ & 0.0474 & 0 & \multirow[t]{3}{*}{$>0.05$} \\
\hline & $\mathrm{Do}^{\mathrm{a}-\mathrm{b}+}$ & $93(0.5886)$ & $92.66(0.5865)$ & 0.9526 & 0 & \\
\hline & $\mathrm{Do}^{\mathrm{a}+\mathrm{b}+}$ & $56(0.3544)$ & $56.67(0.3587)$ & 0.5412 & 0 & \\
\hline \multirow[t]{3}{*}{ Diego } & $\mathrm{Di}^{\mathrm{a}+\mathrm{b}-}$ & $0(0)$ & $0.36(0.0063)$ & 0.4526 & 0 & \multirow[t]{3}{*}{$>0.05$} \\
\hline & $\mathrm{Di}^{\mathrm{a}-\mathrm{b}+}$ & $143(0.9051)$ & $143.38(0.9075)$ & 0.167 & 0 & \\
\hline & $\mathrm{Di}^{\mathrm{a}+\mathrm{b}^{+}}$ & $15(0.0949)$ & $14.27(0.0903)$ & 1.0000 & 0 & \\
\hline \multirow[t]{4}{*}{ Kidd } & $\mathrm{Jk}^{\mathrm{a}+\mathrm{b}-}$ & $45(0.2848)$ & $46.28(0.2929)$ & 0 & 0 & \multirow[t]{4}{*}{$>0.05$} \\
\hline & $\mathrm{Jk}^{\mathrm{a}-\mathrm{b}+}$ & $31(0.1962)$ & $32.37(0.2049)$ & 0.9940 & 0 & \\
\hline & $\mathrm{Jk}^{\mathrm{a}+\mathrm{b}+}$ & $81(0.5127)$ & $77.40(0.4899)$ & 0.0059 & 0 & \\
\hline & $\mathrm{Jk}^{\mathrm{a}-\mathrm{b}-}$ & $1(0.0063)$ & $158.00(1.0000)$ & 0.391 & 0 & \\
\hline \multirow[t]{2}{*}{ Scianna } & $\mathrm{Sc}^{1+2-}$ & $158(1.0000)$ & $0(0)$ & 0 & 0 & \multirow[t]{2}{*}{$>0.05$} \\
\hline & $\mathrm{Sc}^{1-2+}$ & $0(0)$ & $156.11(0.9880)$ & 1.0000 & 0 & \\
\hline \multirow[t]{3}{*}{ Colton } & $\mathrm{Co}^{\mathrm{a}+\mathrm{b}-}$ & $157(0.9937)$ & $0.01(0)$ & 0.8102 & 0 & \multirow[t]{3}{*}{$>0.05$} \\
\hline & $\mathrm{Co}^{\mathrm{a}-\mathrm{b}+}$ & $0(0)$ & $1.85(0.0001)$ & 0.1899 & 0 & \\
\hline & $\mathrm{Co}^{\mathrm{a}+\mathrm{b}+}$ & $1(0.0063)$ & $0(0)$ & 1.810 & 0 & \\
\hline \multirow[t]{5}{*}{ Lutheran } & $\mathrm{Lu}^{\mathrm{a}+\mathrm{b}-}$ & $0(0)$ & $158(1.0000)$ & & 0 & \multirow[t]{2}{*}{$>0.05$} \\
\hline & $\mathrm{Lu}^{\mathrm{a}-\mathrm{b}+}$ & $158(1.0000)$ & $103.71(0.6564)$ & & 0.214 & \\
\hline & $\mathrm{Au}^{\mathrm{a}+\mathrm{b}-}$ & $99(0.6266)$ & $5.70(0.0361)$ & & 3.86 & \multirow[t]{3}{*}{$>0.05$} \\
\hline & $\mathrm{Au}^{\mathrm{a}-\mathrm{b}+}$ & $1(0.0063)$ & $48.62(0.3077)$ & & & \\
\hline & $\mathrm{Au}^{\mathrm{a}+\mathrm{b}+}$ & $58(0.3671)$ & & & & \\
\hline
\end{tabular}

Genetics and Molecular Research 16 (1): gmr16019176 
Comparison of genotype and allele frequencies of 9 rare blood groups between the Uygur population and other ethnic minorities

The allele frequencies are shown in Table 3. Allele frequencies of 9 rare blood groups were obtained among the Uygur population, which were $\mathrm{M}=0.5791, \mathrm{~N}=0.4209, \mathrm{~S}=0.1743$, $\mathrm{s}=0.8009, \mathrm{Fy}^{\mathrm{a}}=0.6994, \mathrm{Fy}^{\mathrm{b}}=0.3006, \mathrm{~K} 1=0.0158, \mathrm{~K} 2=0.9842, \mathrm{Do}^{\mathrm{a}}=0.2342, \mathrm{Do}^{\mathrm{b}}=$ $0.7658, \mathrm{Di}^{\mathrm{a}}=0.0474, \mathrm{Di}^{\mathrm{b}}=0.9526, \mathrm{JK}^{\mathrm{a}}=0.5412, \mathrm{JK}^{\mathrm{b}}=0.4526, \mathrm{Sc} 1=1.0000, \mathrm{Sc} 2=0, \mathrm{Co}^{\mathrm{a}}$ $=0.9940, \mathrm{Co}^{\mathrm{b}}=0.0059, \mathrm{Lu}^{\mathrm{a}}=0, \mathrm{Lu}^{\mathrm{b}}=1.0000, \mathrm{Au}^{\mathrm{a}}=0.8102$, and $\mathrm{Au}^{\mathrm{b}}=0.1899$, respectively. Polymorphism was found in the allele frequencies of 5 rare blood groups, which were MNS, Kidd, Duffy, Dombrock, and Diego. The allele frequencies of the 9 rare blood groups displayed unique features among the Uygur population. Table 3 shows the comparison of the allele frequencies of the 9 rare blood groups among different ethnic minorities in China.

Table 3. Comparison of the allele frequencies of the 9 rare blood groups among different ethnic minorities in China.

\begin{tabular}{|c|c|c|c|c|c|c|c|}
\hline $\begin{array}{l}\text { Rare } \\
\text { blood groups }\end{array}$ & Allele & $\begin{array}{c}\text { Frequency } \\
\text { Uygur population } \\
\text { of Xinjiang } \\
(\mathrm{N}=158)\end{array}$ & $\begin{array}{c}\text { Frequency } \\
\text { Kazak population } \\
\text { of Xinjiang } \\
(\mathrm{N}=196)\end{array}$ & $\begin{array}{c}\text { Frequency } \\
\text { Hui population } \\
\text { of Xinjiang } \\
(\mathrm{N}=220)\end{array}$ & $\begin{array}{c}\text { Frequency } \\
\text { Tibetan population } \\
\text { of Tibet } \\
(\mathrm{N}=409)\end{array}$ & $\begin{array}{l}\text { Frequency } \\
\text { Yi population } \\
\text { of Sichuan } \\
(\mathrm{N}=240)\end{array}$ & $\begin{array}{c}\text { Frequency } \\
\text { Han population } \\
\text { of Chengdu } \\
(\mathrm{N}=332)\end{array}$ \\
\hline \multirow[t]{4}{*}{ MNS } & $\mathrm{M}$ & 0.5971 & 0.6454 & 0.5204 & 0.6809 & 0.6833 & 0.5752 \\
\hline & $\mathrm{N}$ & 0.4209 & 0.3546 & 0.4796 & 0.3191 & 0.3167 & 0.4246 \\
\hline & $\mathrm{S}$ & 0.1743 & 0.1429 & 0.0954 & 0.1467 & 0.9170 & 0.0376 \\
\hline & $\mathrm{s}$ & 0.8009 & 0.8469 & 0.9046 & 0.8533 & 0.9083 & 0.9622 \\
\hline \multirow[t]{2}{*}{ Duffy } & $\mathrm{Fy}^{\mathrm{a}}$ & 0.6994 & 0.7576 & 0.8727 & 0.9218 & 0.9458 & - \\
\hline & $\mathrm{Fy}^{\mathrm{b}}$ & 0.3006 & 0.2423 & 0.1273 & 0.0782 & 0.0292 & - \\
\hline \multirow[t]{2}{*}{ Kell } & K1 & 0.0158 & 0.0026 & 0.0068 & 0 & 0 & - \\
\hline & K2 & 0.9842 & 0.9975 & 0.9932 & 1.000 & 1.0000 & - \\
\hline \multirow[t]{2}{*}{ Dombrock } & $\mathrm{Do}^{\mathrm{a}}$ & 0.2342 & 0.2219 & 0.1386 & 0.1504 & 0.1250 & 0.0663 \\
\hline & $\mathrm{Do}^{\mathrm{b}}$ & 0.7658 & 0.7780 & 0.8614 & 0.8496 & 0.8750 & 0.9337 \\
\hline \multirow[t]{2}{*}{ Diego } & $\mathrm{Di}^{\mathrm{a}}$ & 0.0474 & 0.0357 & 0.0159 & 0.0342 & 0.0167 & 0.0407 \\
\hline & $\mathrm{Di}^{\mathrm{b}}$ & 0.9526 & 0.9643 & 0.9841 & 0.9658 & 0.9833 & 0.9593 \\
\hline \multirow[t]{2}{*}{ Kidd } & $\mathrm{JK}^{\mathrm{a}}$ & 0.5412 & 0.5383 & 0.4953 & 0.5513 & 0.5250 & 0.4428 \\
\hline & $\mathrm{JK}^{\mathrm{b}}$ & 0.4526 & 0.4567 & 0.5045 & 0.4487 & 0.4750 & 0.5572 \\
\hline \multirow[t]{2}{*}{ Scianna } & Sc1 & 1.0000 & 1.0000 & 1.0000 & 1.0000 & 1.0000 & - \\
\hline & Sc2 & 0 & 0 & 0 & 0 & 0 & - \\
\hline \multirow[t]{2}{*}{ Colton } & $\mathrm{Co}^{\mathrm{a}}$ & 0.9940 & 0.9924 & 0.9932 & 0.9976 & 1.0000 & - \\
\hline & $\mathrm{Co}^{\mathrm{b}}$ & 0.0059 & 0.0077 & 0.0068 & 0.0024 & 0 & - \\
\hline \multirow[t]{4}{*}{ Lutheran } & $\mathrm{Lu}^{\mathrm{a}}$ & 0 & 0 & 0 & 0 & 0 & - \\
\hline & $\mathrm{Lu}^{\mathrm{b}}$ & 1.0000 & 1.0000 & 1.0000 & 1.0000 & 1.0000 & - \\
\hline & $\mathrm{Au}^{\mathbf{a}}$ & 0.8102 & 0.8495 & 0.9091 & 0.9108 & 1.0000 & - \\
\hline & $\mathrm{Au}^{\mathrm{b}}$ & 0.1899 & 0.1505 & 0.0909 & 0.0892 & 0 & - \\
\hline
\end{tabular}

\section{Electrophoresis results of genotypes of 9 rare blood groups in one Uygur subject}

The electrophoretograms of the genotypes at 22 gene loci are presented in Figure 1. The bands were clear and the positive bands were distinguished from the internal control bands with parallel and equal displacement. The results can be easily interpreted.

\section{DISCUSSION}

The frequency of the $\mathrm{M}$ allele in the $\mathrm{MN}$ blood group system was detected as 0.5791 in the Uygur population of Xinjiang. It is consistent with the frequency of the $\mathrm{M}$ allele in the Han population of Tai'an City in Shandong Province, the Han population of Jiangxi, the Han population in Guangdong and Fujian Province, and the Han population in Chengdu of Sichuan

Genetics and Molecular Research 16 (1): gmr16019176 


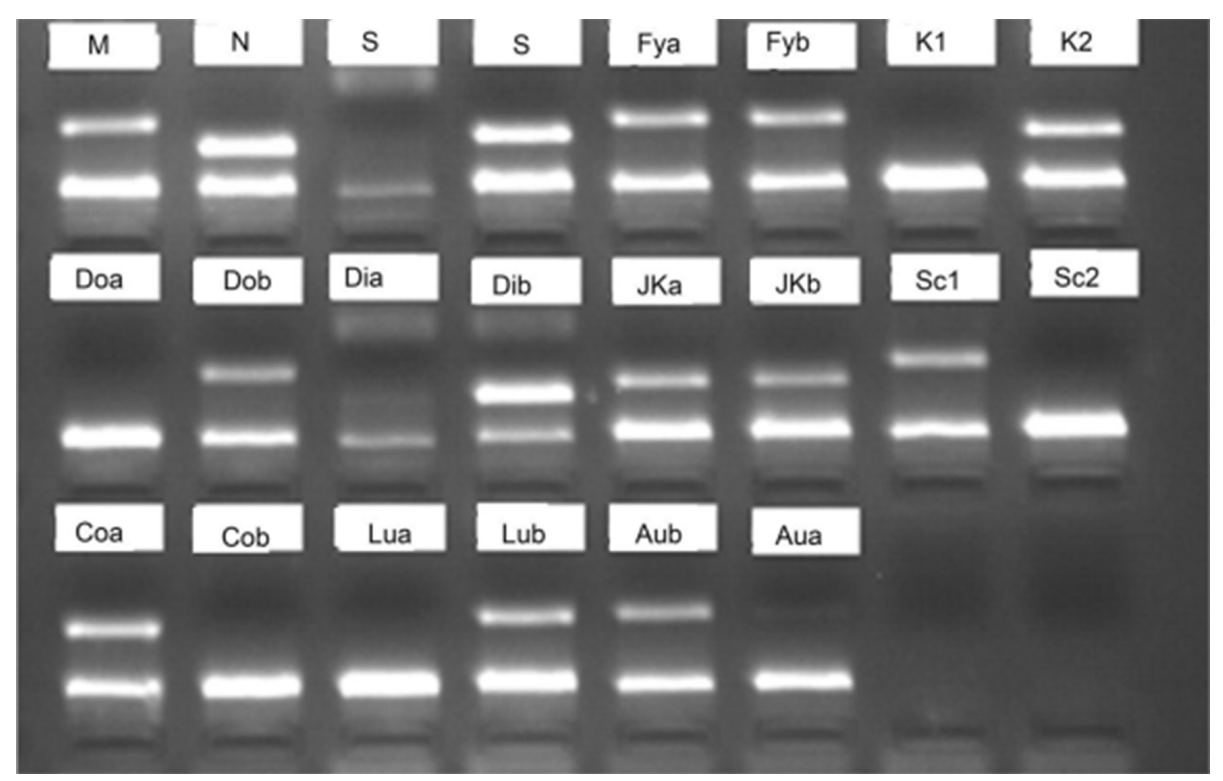

Figure 1. Electrophoretograms of genotypes of 9 rare blood groups in one Uygur subject. Genotypes of the MNS, Duffy, Kell, Dombrock, Diego, Kidd, Scianna, Coltonand Lutheran rare blood groups were $\mathrm{M}^{+} \mathrm{N}^{+}, \mathrm{S}^{-} \mathrm{s}^{+}, \mathrm{Fy}^{\mathrm{a}+b+}, \mathrm{K}^{1-2+}$, $\mathrm{Do}^{\mathrm{a}-\mathrm{b}+}, \mathrm{Di}^{\mathrm{a}-\mathrm{b}+}, \mathrm{Jk}^{\mathrm{a}+\mathrm{b}+}, \mathrm{Sc}^{1+2-}, \mathrm{Co}^{\mathrm{a}+\mathrm{b}-}, \mathrm{Lu}^{\mathrm{a}-\mathrm{b}+}$, and $\mathrm{Au}^{\mathrm{a}-\mathrm{b}+}$, respectively.

province, which is $0.5229,0.5428,0.5827$, and 0.5752 , respectively (Meng et al., 2001; Li et al., 2001; Ye et al., 2001; Guo and Guo, 2005; Hong et al., 2012; Zhang et al., 2014). However, the frequency of the $M$ allele in the Uygur population is lower than that found in the Tibetan population in Tibet, which is 0.6809 (Zhang et al., 2014). The frequency of $\mathrm{N}$ allele was 0.4209 in the Uygur population, which is also consistent with that found in other ethnic minorities of China. The frequencies of S and s alleles are rarely reported in China. We found the frequency of S allele in the Uygur population was 0.1743 , which is much higher than that in the Tibetan population of Tibet (0.1467) (Zhang et al., 2014), the Han population of Chengdu in Sichuan Province (0.0376) (Hong et al., 2012), and the Hui population of Xinjiang (0.0954) (Lin et al., 2016). Thus, the Uygur population displayed some unique features in allele frequencies of the 9 rare blood groups. Moreover, there were 6,105, and 43 cases carrying SS, ss, and Ss genotypes, respectively, and a rare $\mathrm{S} s$ phenotype was found in 2 cases, with a frequency of only 0.0102 . The S s phenotype has not been reported previously in China. The alleles of the 9 rare blood groups in the Uygur population of Xinjiang are featured by high expression and high polymorphism. Based on this feature, countermeasures can be adopted for meeting the blood transfusion needs in ethnic minorities in Western China.

The Duffy blood group system was first discovered in 1950 (Zhao and Li, 2009). As an important erythrocyte blood group, the Duffy blood group mainly produces the IgG1 antibody, which can cause acute and delayed transfusion reactions. The frequency of Fy antigens is above 0.9700 in China, Japan, and North Korea; not above 0.6600 in individuals of Europeandescent, 0.1000 in Africans, and 0 in individuals belonging to the Central African Republic, and all the Central African individuals carry the Fy(a-b-) phenotype. However, the Fy (a-b-) phenotype is very rare in individuals of European-descent and Asians (Zhao and Li, 2009).

Genetics and Molecular Research 16 (1): gmr16019176 
In our study, the frequency of Fy antigen was 0.6694 in the Uygur population of Xinjiang, which is significantly lower than that found in the Tibetan population of Tibet (0.9218) (Zhang et al., 2014), the Han population of Jiangsu (0.9400) (Liu et al., 2012), the Han population of Luoyang (0.9527) (Yang et al., 2012), the Han population of Zhejiang (0.9412) (Fu et al., 2001a) and the Han population of Shanghai (0.9649) (Zhao and Li, 2009). It is easy to see that given the unique allele frequencies of the rare blood groups in Uygur population, more efforts should be devoted to the screening of rare blood groups in case of emergency use.

In the Dombrock blood group system, the frequency of the $\mathrm{Do}^{\mathrm{a}}$ antigen is lower in individuals of African-descent, American Indians, and Asians, and lower in individuals of European-descent belonging to Northern Europe and USA. The positive rate of $\mathrm{Do}^{\mathrm{a}}$ antigen is $67 \%$ in individuals of European-descent, $55 \%$ in individuals of African-descent, $24 \%$ in the Japanese, and 0.1400 in Thai people (Delanghe et al., 1995; Grassineau et al., 2007; Li et al., 2010). The frequency of the $\mathrm{Do}^{\mathrm{a}}$ antigen was 0.2342 in the Uygur population of Xinjiang, which is consistent with that reported for the Uygur population of Xinjiang (0.2559) (Wu et al., 2001); however, it is much higher than that in the Tibetan population of Tibet and the Han population of Chengdu in Sichuan Province (0.0663) (Hong et al., 2012), the Han population of Shanghai (0.0614) (Zhao and Li, 2009), and the Han population of Xi' an City (0.1159) (Liu and Liu, 2003). This fully demonstrates the large variation in allele frequencies of the rare blood groups across the regions and ethnic groups.

The frequency of $\mathrm{Di}^{\mathrm{a}}$ antigen in the Diego blood group system is 0.0474 in the Uygur population of Xinjiang, which is much higher than that found in the Tibetan population of Tibet (0.0342) (Zhang et al., 2014), the Han population of Chengdu in Sichuan Province (0.0407) (Hong et al., 2012), the Han population of Xi' an City (0.0250) (Liu and Liu, 2003), and the Han population of Jiangxi Province (0.0198) (Xiao et al., 2010). Given the higher frequency of $\mathrm{Di}^{\mathrm{a}}$ antigen in the Uygur population of Xinjiang, more efforts should be undertaken in preparation for emergency blood transfusion for the Uygur population. However, in Zhang et al. (2014), the allele frequencies of Duffy, Kell, Diego, Scianna, Colton, and Lutheran blood groups in the Uygur population are reported as similar to those in other studies. We found that the frequency of the $\mathrm{Di}^{\mathrm{a}}$ antigen in the Uygur population of Xinjiang was different compared with other Chinese ethnic minorities.

The frequencies of antigens of the Kidd blood group vary from one ethnic group to another. In individuals of European-descent and African-descent, the frequency of $\mathrm{Jk}^{\mathrm{a}}$ antigen is slightly higher than that of $\mathrm{Jk}^{\mathrm{b}}$ antigen (Hashmi et al., 2007). In the Chinese Han population, the frequency of the $\mathrm{Jk}^{\mathrm{b}}$ antigen is slightly higher than that of the $\mathrm{Jk}^{\mathrm{a}}$ antigen ( $\mathrm{Fu}$ et al., 2001b; Song et al., 2008). The frequency of the $\mathrm{Jk}^{\mathrm{a}}$ and $\mathrm{Jk}^{\mathrm{b}}$ antigens is 0.54212 and 0.4526 , respectively, in the Uygur population of Xinjiang. The allele distribution of the Kidd blood group in the Uygur population is more similar to that of individuals of European-descent and different from the Chinese Han population. The frequency of the Jka antigen $(0.5421)$ in the Uygur population, is consistent with that found in the Tibetan population of Tibet (0.5513) (Zhang et al., 2014), the Uygur population of Xinjiang (0.5429) (Qiu et al., 2012), the Han population of Zhejiang (0.4902) (Fu et al., 2001b), the Han population of Chengdu (0.4428) (Hong et al., 2012), the Hui population of Xinjiang (0.4504) (Qiu et al., 2012), and the Hui population of Xinjiang in another studies (0.4955) (Lin et al., 2016). Apparently, the Uygur population of Xinjiang exhibits a distinctive feature in the allele frequencies of the rare blood groups as compared with the Han and Hui population. The reasons mainly lie in the origin and migration of the ethnic group.

Genetics and Molecular Research 16 (1): gmr16019176 
It is reported that the frequency of the $\mathrm{Jk}(\mathrm{a}-\mathrm{b}-)$ phenotype is below $0.01 \%$ in the Asian population but higher in Indians, Bolivians, and individuals of European-descent (Song et al., 2008). This phenotype has been found in Macao Blood Center (Liu, 2011). Individuals carrying this rare phenotype are difficult to identify using serological tests (Li et al., 2010). Yan (2007) identified 10 individuals out of 50,034 donors carrying the Jk(a-b-) phenotype, with a frequency of 0.0002 . We reported a frequency of 0.0272 in the Hui population of Xinjiang (Lin et al., 2016), with 6 subjects carrying this rare phenotype. This phenotype has not been yet discovered in the Tibetan population of Tibet (Zhang et al., 2014). This study identified a single Uygur subject carrying the Jk(a-b-) phenotype, with a frequency of 0.0051 , which is higher than that among the Asian population $(0.01 \%)$. Therefore, it is demonstrated that genetic migration among the Uygur population of Xinjiang is related to individuals of European-descent in middle Asia, and this finding is of high significance for blood transfusion and construction of the rare blood group library for ethnic minorities. More work should be done in rare blood group screening based on a full exploitation of the local rare blood group resource.

The observed and expected values of allele and genotype frequencies of 9 rare blood groups were compared using the chi-square test, and no significant difference was found (P $>0.05$ ). The frequencies obeyed the Hardy-Weinberg equilibrium, indicating constant allele frequencies of rare blood groups in Uygur population of Xinjiang.

A skewed distribution pattern was found for the allele frequencies of 2 rare blood groups, Kell and Diego, for which the genotype frequency was 0 . This agrees with the distribution patterns reported for the Tibetan and Han populations. The allele frequencies of the Scianna, Colton, and Lutheran rare blood groups indicated monomorphism, as was consistent with the frequency distribution in the Tibetan and Han populations. The allele frequencies of the MNS, Duffy, Kidd, and Dombrock rare blood groups indicated high polymorphism, which is different from other ethnic minorities. In the comparison of the rare blood groups MNS, Duffy, Kell, Dombrock, Diego and Kidd of Xinjiang Uygur, Kazak, Hui, Tibetan, Sichuan and Chengdu, the highest frequency of gene was found in Xinjiang Uygur K1 0.0158, Doa 0.2342 , The highest tribe of the Tibetan Han nationality is 0.6822 , Dob 0.9337 and JKb 0.5572 are the highest; the Xinjiang Kazuya is the highest; the Tibetan Tibetan is the highest; the Tibetan Tibetan Fyb 0.0782, JKa 0.5513 is the highest; the Tibetan Yi M 0.6833, S 0.9170 is the highest; Gene antigen frequency were not the highest.The above results not only contribute in understanding the genetic background of rare blood groups and historical migration for the Uygur population of Xinjiang, but are also valuable for precision blood transfusion, reducing hemolytic transfusion reaction, and matching in organ transplantation.

However, the sample size is limited due to limited funding. Moreover, the PCRSSP method is a qualitative and sensitive assay and some subjectivity is involved in result interpretation, which could lead to errors.

\title{
Conflicts of interest
}

The authors declare no conflict of interest.

\section{ACKNOWLEDGMENTS}

\author{
Research supported by “474” People’s Liberation Army Hospital, Urmqi, China,
}


and compiled by the PCR Room Department of Blood Transfusion. Fund Project: Lanzhou Military Region Medical and Health Research Project (\#CLZ15JB26).

\section{REFERENCES}

Chen RC, Lin J, Lin B and Lin PP (2014). Screening and clinical application of Jk (a-b-) in blood donors in Wenzhou. Chin. J. Blood Transf. 27: 1132-1133.

Delanghe J, Duprez D, de Buyzere M, Robbrecht D, et al. (1995). MN blood group, a genetic marker for essential arterial hypertension in young adults. Eur. Heart J. 16: 1269-1276. http://dx.doi.org/10.1093/oxfordjournals.eurheartj.a061085

Fu QH, Jin L, Hong XZ, He J, et al. (2001a). Genetyping of the Duffy blood group. Shanghai J. Med. Lab. Sci. 16: 140141.

Fu QH, He J, Hong XZ, Jin L, et al. (2001b). Genotyping of Kidd blood group in Zhejiang Han Nationality. Chin. J. Blood Transf. 14: 240-241.

Grassineau D, Papa K, Ducourneau A, Duboz P, et al. (2007). Improving minority blood donation: anthropologic approach in a migrant community. Transfusion 47: 402-409. http://dx.doi.org/10.1111/j.1537-2995.2007.01130.x

Guo JG and Guo HY (2005). Investigation and correlation analysis of ABO, Rh, MN, P blood group distribution in unpaid blood donors in Tai'an city of Shandong province. Commun. Med. 3: 19-21.

Hashmi G, Shariff T, Zhang Y, Cristobal J, et al. (2007). Determination of 24 minor red blood cell antigens for more than 2000 blood donors by high-throughput DNA analysis. Transfusion 47: 736-747. http://dx.doi.org/10.1111/j.15372995.2007.01178.x

Hong Y, Gong TX, Zhou CH, Wang NH, et al. (2012). Genotyping of nine blood group antigens in Kell and other blood donors. Chin. J. Blood Transf. 25: 763-765.

Ji YL, Wei L, Wang Z and Zhao Y (2012). Screening and molecular genetics of Jk(a-b-) phenotype in volunteer blood donors in Guangzhou. Chin. J. Blood Transf. 25: 216-219.

Li GL, Xiao L, Sun Y, Fang CF, et al. (2001). Investigation of ABO, Rh, MN, Kidd, Lewis and P blood group system in Han Population of Jiangxi Province. Chin. J. Blood Transf. 14: 96.

Li Q, Han SS, Guo ZH, Yang Y, et al. (2010). The polymorphism of the Knops blood group system among five Chinese ethnic groups. Transfus. Med. 20: 369-375. http://dx.doi.org/10.1111/j.1365-3148.2010.01023.x

Lin GY, Shan JJ, Zhang YN, Zhang YQ, et al. (2016). A study on gene frequency of 9 rare blood groups in Hui ethnic group. J. Xinj. Med. Univ. 39: 1026-1031.

Liu ML and Liu S (2003). Genotyping of Dombrock blood type in Han nationality in Xi'an. Chin. J. Blood Transf. 16: 256-257.

Liu Z, Zeng R, Chen Q, Li M, et al. (2012). Genotyping for Kidd, Kell, Duffy, Scianna, and RHCE blood group antigens polymorphisms in Jiangsu Chinese Han. Chin. Med. J. (Engl.) 125: 1076-1081.

Liu DZ (2011). Rare blood group work in China's development. Chin. J. Blood Transf. 14: 12-17.

Meng QB, Lan JZ and Zhang Y (2001). MN blood type PCR-SSP genotyping. Chin. J. Blood Transf. 14: 296-297.

Qiu F, Tian XM, Gulibahaoer and Hu AH (2012). Investigation of Kidd blood group gene frequency in Uygur and Hui populations in Northern. Chin. J. Blood Transf. 25: 682-683.

Roychoudhury AK and Nei M (1988). Human polymorphic genes world distribution [M]. Oxford University Press, New York.

Shulman IA (1990). The risk of an overt hemolytic transfusion reaction following the use of an immediate spin crossmatch. Arch. Pathol. Lab. Med. 114: 412-414.

Song N, Zheng SR, Yao ZQ, Wei TX, et al. (2008). Investigation of Kidd blood group system gene frequency in Sichuan Han Population. Chin. J. Blood Transf. 21: 926-927.

Wang G, Wang GJ, Wang LP and Sang JQ (1993). Distribution of Duffy and Kell blood type in Mongolian. Chin. J. Hematol. 14: 432.

Wu GG, Jin S, Deng Z and Zhao T (2001). Studies of DO gene frequency in the Chinese Han and Uighur Nationalities. Transfusion 41: 102.

Xiao L, Wu H, Li GL, Sun Y, et al. (2010). Frequency distribution of Diego blood type gene in Han population in Jiangxi province. J. Exp. Med. Lab. Med. 28: 427.

Yan KF (2007). Screening of rare blood types of blood donors in Panyu District, Guangzhou City. Chin. J. Blood Transf. 20: 290-291.

Yan L, Zhu F, Fu Q and He J (2005). ABO, Rh, MNS, Duffy, Kidd,Yt, Scianna, and Colton blood group systems in indigenous Chinese. Immunohematology 21: 10-14.

Genetics and Molecular Research 16 (1): gmr16019176 
Yang B, Lv YL, Ma HL and Lan JC (2012). Genotype distribution of Duffy Bblood type in Han population of Luoyan. Clin. Blood Transf. Lab. Med. 14: 32-34.

Yang DB, Chen MT, Liu L, Yang HC, et al. (2014). Challenges and strategies of self-sufficiency of blood products in China. Chin. J. Blood Transf. 27: 1096-1099.

Ye X, Luo GP, Xiao LL, Fu YS, et al. (2001). Investigation of MN blood group distribution and gene frequency in Guangdong and Fujian Han nationality. Guangzhou Med. 32: 53-54.

Zhang R, Tian L, Li XJ, Yao ZQ, et al. (2014). Genetic polymorphism of multiple red blood cell types in Tibetan Population. Chin. J. Blood Transf. 27: 505-507.

Zhao XM and Li Z (2009). Genetic polymorphisms of 42 rare blood group antigens in nine red blood cell systems of Shanghai Han population. Clin. Blood Transf. Lab. Med. 11: 321-325.

Zhou HG, Jin L and Fu QH (2001). Investigation of Kidd and Duffy blood type genotypes in She nationality in Zhejiang Province. Chin. J. Blood Transf. 14: 239.

Genetics and Molecular Research 16 (1): gmr16019176 